\title{
Towards Standardized Dissolution Techniques for In Vitro Performance Testing of Dry Powder Inhalers
}

\author{
Andreea Floroiu ${ }^{1,2, *}$, Martin Klein ${ }^{1}$, Johannes Krämer ${ }^{1}$, and Claus-Michael Lehr ${ }^{2}, 3$ \\ ${ }^{1}$ Eurofins - PHAST Development GmbH \& Co. KG, Konstanz, Germany \\ ${ }^{2}$ Department of Biopharmaceutics and Pharmaceutical Technology, Saarland University, Saarbrücken, Germany \\ ${ }^{3}$ Helmholtz Institute for Pharmaceutical Research Saarland (HIPS), Saarbrücken, Germany
}

\section{ABSTRACT}

e-mail: andreea.floroiu@phast.com

The pulmonary route of administration is used for both locally and systemically acting drugs. However, knowledge gaps about the fate of aerosol particles after deposition in the lung provide room for future elucidation. During pharmaceutical development as well as in quality control of oral inhalation products, in vitro performance tests are required for discriminating between formulations and to prove batch-to-batch consistency. Although the aerodynamic particle size distribution is widely recognized as the pivotal performance parameter, there is still no standardized test for in vitro dissolution testing. This review summarizes the in vitro performance testing methodologies developed for orally inhaled drug product (OIDP) evaluation, with a focus on dissolution testing of dry powders for inhalation. The dissolution setups used, together with the media, membranes, and methods employed for collecting the relevant particle fraction, are presented. With a clear focus on in vitro dissolution testing, particle size distribution is regarded as a physical reduction to the relevant moiety of the specimen to be sampled for subsequent testing.

KEYWORDS: Dissolution testing, dry powder inhaler, orally inhaled drug products, aerodynamic particle size

\section{INTRODUCTION}

The lung as a delivery site for drugs has had growing interest in the treatment of systemic and local diseases. It provides a large surface $(>100$ $\mathrm{m}^{2}$ ) of a very thin epithelial layer $(0.2-0.7 \mu \mathrm{m})$ with good permeability and high blood perfusion, which is suitable for the delivery of drugs $(1,2)$. Furthermore, the respiratory tract represents a noninvasive route for certain small molecules and biologics, occasionally with increased bioavailability by avoiding the liver first pass effect $(3,4)$. The complexity of the lung is reflected in its architecture and in the heterogeneity of the surface. In the upper airways, a ciliated epithelium is covered by a relatively thick mucus layer, and the peripheral alveolar cell surface is lined by a very thin layer of lung fluid, which includes a broad range of surfactants (5). The lung has evolutionarily developed for gas exchange. It acts also as an efficient separator for airborne particles due to the branched architecture and the ability to remove non-gaseous material by innate mechanisms, like the mucociliary escalator and macrophage clearance (6).

For the treatment of local inflammation or other respiratory diseases, orally inhaled drug products
(OIDPs) have been used for more than 50 years $(4,7)$. In 2006, insulin for the treatment of diabetes mellitus via the respiratory tract was introduced (4), but was soon after withdrawn from the market because of safety and efficacy concerns. Since then, several other drug substances for treatment of local and systemic diseases have been subjected to development of formulations suitable for pulmonary drug delivery (8-11). However, as attractive as the lung can be for drug delivery purposes, there are major regulatory, technical, and scientific hurdles to overcome and research to be completed. Within the scope of this article, the most important question to address is the fate of inhaled particles after deposition in the target region of the lung. Orally inhaled particles undergo impaction, sedimentation, or diffusion, depending on their aerodynamic particle size. It has been shown that particles with a size ranging from 0.5 to $4 \mu \mathrm{m}$ undergo sedimentation in the alveolar regions, which is considered the preferred location for deposition of active pharmaceutical ingredients (APIs) in the lung $(12,13)$. Larger particles impact on the walls of the upper airways and are cleared by the mucociliary apparatus (MCA) and swallowed. In contrast, the movement of particles smaller than $0.5 \mu \mathrm{m}$ is mainly controlled by diffusion, with the risk

* Corresponding author. 
of being exhaled (12). According to generally accepted models, there is a theoretical deposition maximum for particles with a mass median aerodynamic diameter (MMAD) of $2 \mu \mathrm{m}$, which is often considered a target for optimizing a pharmaceutical aerosol. Interestingly, according to the same models, there is a second, even more pronounced deposition maximum for ultra-fine particles of a size around $20 \mu \mathrm{m}$. Although its toxicological significance is obvious, e.g., in the context of cigarette smoke or diesel exhaust, this particle size is still widely unexplored for pharmaceutical aerosols, possibly due to the lack of adequate technologies to generate such small particles of drug substances.

Bioavailability primarily depends upon the properties of the drug product, including the physicochemical properties of the drug substance, the dose administered, and the absorption and metabolization associated with the site, and the rate of absorption (13). In case of solid dosage forms delivered via the gastrointestinal (GI) tract, a comparably large volume of fluid is available for dissolution. In contrast, the respiratory tract provides a large surface $\left(>100 \mathrm{~m}^{2}\right)$ covered by a liquid layer that varies in thickness $(60 \mu \mathrm{m}$ in the trachea, $8-10 \mu \mathrm{m}$ in the bronchi, $3 \mu \mathrm{m}$ in the bronchioles, $0.07 \mu \mathrm{m}$ in the alveoli), resulting in a total volume of $15-70 \mathrm{~mL}$ in healthy humans and may show high heterogeneity in the population suffering from pulmonary diseases $(3,5,14,15)$.

The challenge to dissolve solids in a very limited volume is greater in the case of drug substances with low aqueous solubility, resulting in poor dissolution behavior in the limited physiological volumes of aqueous media (16). Therefore, the dissolution rate can be the rate-limiting step for systemic availability of dry powder inhalers (DPIs), and currently, no standardized in vitro dissolution test is available for investigation of the in vitro performance, as a predictive tool for characterizing DPIs $(17,18)$.

In the field of pharmaceutical quality, the regulatory guidelines of the US Food and Drug Administration (FDA) and European Medicines Agency (EMA) recommend the determination of the delivered dose and the aerodynamic particle size distribution (APSD), while dissolution testing is not yet required $(19,20)$.

In 2008, the USP Ad Hoc Inhalation Advisory Panel recommended not to pursue the development of standardized dissolution testing methods for DPIs (15). The International Pharmaceutical Aerosol Consortium on Regulation and Science (IPAC-RS) Dissolution Working
Group followed this recommendation in 2012 due to a lack of precision and robustness of methodology at that time (17). This creates a demand for valid standardized in vitro dissolution methods to be used in drug product development and quality control (21). There is a great need for predictive in vitro testing, particularly for locally acting drug products where the determination of the classical in vivo surrogate method for therapeutic efficacy (i.e., bioavailability) is not applicable.

In the developmental phase of locally acting DPIs, in vitro dissolution testing is preferably used to predict differences in the in vivo performance (22). Furthermore, APSD alone might be misleading, as two formulations with similar APSD may not necessarily have a similar pharmacokinetic (PK) profile (23). More recently (2015), it was stated that there is a need to develop relevant in vitro dissolution testing methods for predicting DPIs performance (24). The dissolution behavior of OIDPs was presented as the critical quality attribute for poorly soluble drug substances (25).

As for any route of administration there is a relevant impact of the dosage form on the in vivo performance, which in case of inhaled aerosol powders will relate to the drug's solubility and dissolution rate. The same holds also true for pressurized metered dose inhalers (pMDIs), which also generate solid particles after the propellant has evaporated. Therefore, meaningful in vitro dissolution testing is needed for most types of OIDPs $(13,26)$.

As research, method development, and data interpretation regarding in vivo performance of orally administered drug products greatly benefit from referring to a biopharmaceutical classification system (BCS), the wish of implementing a similar system for the OIDPs started being discussed $(27,28)$. The development of an analogous BCS for pulmonary drugs may be based on the same pivotal parameters as used for oral administration. Among those are solubility of the drug substance in defined media and permeability in a defined segment of the lung, together with the dissolution rate of the drug product $(13,29)$.

This review article intends to summarize recent developments in performance testing of DPIs, with a focus on selection of the relevant particle size fraction prior to dissolution testing and the application of methods for in vitro dissolution testing. Either alone or in combination, APSD and dissolution testing are pivotal for biopharmaceutical characterization. 


\section{DEVICES FOR PULMONARY DRUG DELIVERY}

Metered dose inhalers (MDIs) are the most commonly used devices due to their reliable handling for administering a defined dose by inhalation. A defined dose is expelled as a fine mist of small droplets when the drug is applied as a solution, or as solid particles in the case of suspensions, by using a pressurized propellant. Although they are easy to use, the efficiency of MDIs depends on the user's coordination between inhalation and device actuation. Spacers or holding chambers may be used to make this step less critical (30-32). Nebulizers actively aerosolize liquid drug formulations using compressed air or ultrasonic energy, while constantly delivering aerosol for inhalation $(31,33)$.

In the case of DPIs, micronized drug particles are often bound to large carrier particles consisting of lactose (34). Upon aerosolization by the user's inhalation, the mixture becomes deagglomerated. While the carrier particles impact on the upper airways, the active drug particles ideally undergo sedimentation in the peripheral lung. With DPIs, there is no need to coordinate the inhalation with the inhaler actuation, and the API as well as excipients are present in a powder form, which generally has better physico-chemical stability than solutions or suspensions. However, their efficiency depends on the user's inhalation strength and duration $(30,32,35)$.

An important aspect of these devices - the delivery of an effective dose to the desired location in the lung is closely linked to the particle size distribution of the aerosolized drug, which is a critical factor of the drug product's performance.

\section{ANALYSIS OF PARTICLE SIZE DISTRIBUTION}

From the perspective of running a dissolution experiment, DPIs require a greater scrutiny when it comes to apply the dosage forms. Unlike for oral dosage forms, the medication is produced in situ and with the prominent parameters: delivered dose by a single actuation, and total surface area, which is mainly determined by the particle size distribution within the range of 0.5-4 $\mu \mathrm{m}$. As already mentioned, one of the most important parameters for characterizing DPIs is the APSD. APSD quantifies the drug particle fractions with a relevant aerodynamic size for reaching the targeted area in the lung.

Presently, three devices for APSD measurement are described in both USP and European Pharmacopeia: the Multi Stage Liquid Impinger (MSLI), Andersen Cascade Impactor ( $\mathrm{ACl})$, and Next Generation Impactor (NGI). Besides these, the Twin (Glass) Impinger and MarpleMiller Impactor are recommended by the USP or
European Pharmacopeia individually (36). The MSLI is still widely used, but the resolution in the size range of interest is reduced compared to the $\mathrm{ACl}$ and $\mathrm{NGI}$.

Cascade impaction uses particle inertia for measurement of particle size distribution. This allows the determination of particle size and the distribution of the dose delivered. The $\mathrm{ACl}$ (Fig. 1B) is originally designed with eight stages, a resolution in the range from $0.4-9 \mu \mathrm{m}$, and an air flow rate of $28 \mathrm{~L} / \mathrm{min}$. For performance testing of DPIs requiring higher flow rates, conversion to 60 and $90 \mathrm{~L} / \mathrm{min}$ is feasible (32).

Unlike the $\mathrm{ACl}$, which was originally developed for environmental pollution studies, the NGI (Fig. 1A) was designed by collaborative efforts of pharmaceutical companies to overcome the limitations of the $\mathrm{ACl}$. The NGI delivers reproducible fractions of particles in the range of $0.5-5.0 \mu \mathrm{m}$, using flow rates from 15 to $100 \mathrm{~L} / \mathrm{min}$. However, full resolution cascade impaction measurements are not only time consuming, but they also require a high degree of skill, consistency, and experience from laboratory scientists to avoid analytical artifacts (37). For routine quality control and fast screening in the developmental phase of DPIs, abbreviated impactor measurement (AIM) devices have been suggested, provided that reliable, full-resolution size distribution data are already available (32).

Due to the modular construction of cascade impactors, tailoring to the stage of interest can be applied (32). For research applications aiming to target relevant locations in the lung, the particle size range of interest can be chosen (38). Fast Screening Andersen (FSA), an abbreviated version of the standard $\mathrm{ACl}$, and the Fast Screening Impactor (FSI), which uses a pre-separator and the same induction port as the NGI, are commercially available AIM devices that allow the separation of particles under $5 \mu \mathrm{m}$ (32).

Non-impactor-based APSD measurement techniques (Table 1) for aerosols in the size range of interest also allow rapid scanning for the DPIs evaluation in the development phase, but for regulatory approval, the use of a compendial test is preferred.

\section{PARTICLE COLLECTION FOR DISSOLUTION PURPOSE}

A first step towards dissolution testing is the collection of particles on an adequate support that can be used with the chosen dissolution setup. The most important parameters of this step were shown to be the uniformity of particle distribution in the layer deposited on the 
A

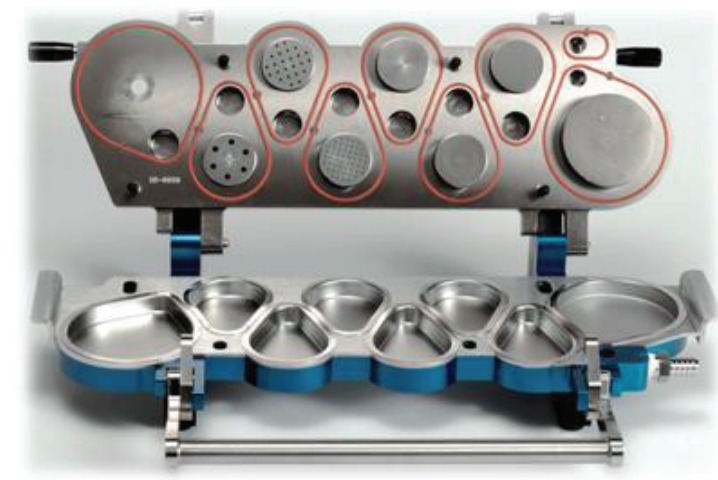

B

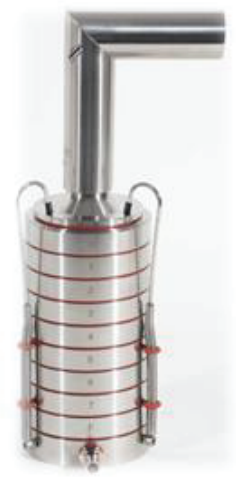

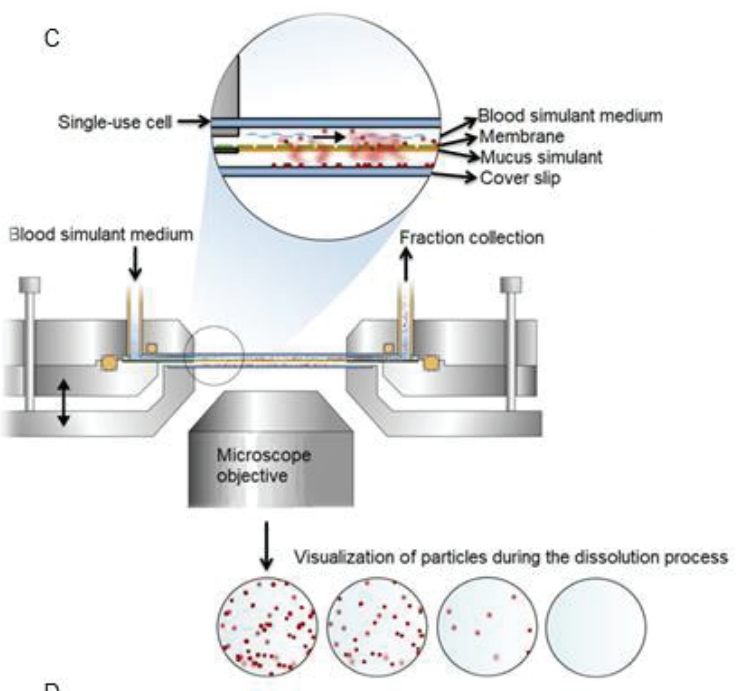

D

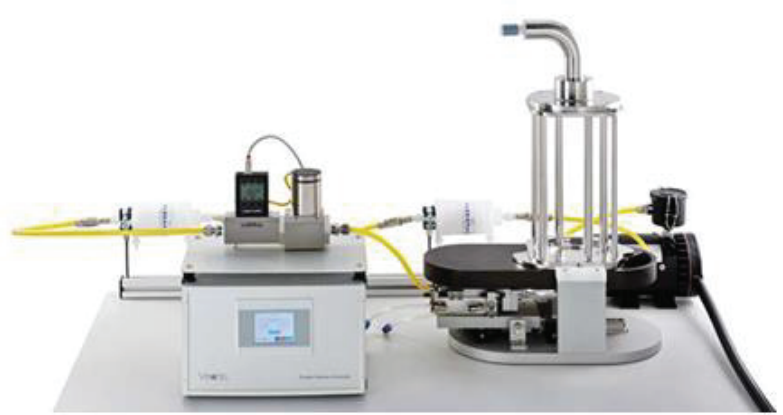

Figure 1. Visual representation of the two most common devices used for aerodynamic particle size distribution measurements: New Generation Impactor (A) and Andersen Cascade Impactor (B), together with the Vitrocell Dry Powder Chamber, a device for particle collection based on time-of-flight and sedimentation (D), and a schematic of the Dissolvlt in vitro dissolution and absorption tool (C).

Sources: (A, B) Reprinted with permission from Copley Scientific: Inhaler Testing Brochure 2015. http://www.copleyscientific.com/downloads/ brochures. (C) Modified with permission from Inhalation Sciences, http://www.preciseinhale.com/explore/8-exposure-modules-1-system/ dissolvit/, Copyright 2018 Inhalation Sciences Sweden AB. (D) Reprinted with permission from Vitrocell Systems, https://www.vitrocell.com/ inhalation-toxicology/exposure-systems/vitrocell-powder-chamber.

collection surface and the APSD of the collected fraction compared to that of the emitted aerosol (39, 40). Dissolution testing can be done on representative samples of the polydisperse aerosol or on a selected size class of the aerosol particles (fine particle fraction (FPF) or fine particle dose (FPD)). The FPD is defined as the entire dose below a specific particle size, generally $5 \mu \mathrm{m}$. The methods used for particle deposition belonging to the first category are those that do not have a particle separation step based on aerodynamic size. The airbrush method, manual sprinkling, dry powder insufflators, and the Preciselnhale aerosol generator are described for particle deposition with the purpose of subsequent dissolution testing of DPIs (41-44). Several methods are available for isolating the FPD. The most frequently encountered are variations of the abbreviated impactor method. An abbreviated $\mathrm{ACl}(\mathrm{aACl})$ is used by leaving out specific stages from the modular $\mathrm{ACl}(45,46)$. Alternatively, the $\mathrm{NGI}$ can be used for particle collection by placing a carrier, such as membrane filter, on one of the stages to collect particles (47). Also, a special cup with an impaction insert that can be directly transferred in the dissolution vessel is commercially available for use with the NGI (48). In most of these cases, the collection support with the particles has to be transferred from the device used for deposition to the dissolution setup. Error of this transfer is a potential source of high variability in the final results. The Transwell setup, where the particles are collected directly on the membrane of the wells for dissolution testing avoids the "transfer error". Although the concept of abbreviated impactors represents a major step towards precision, practicality, and time savings, the thickness of the deposited particle layer on top of the membrane at individual stages can affect the dissolution rate of 
Table 1. Analytical APSD Measuring Techniques

\begin{tabular}{|c|c|c|c|c|c|}
\hline Method & $\begin{array}{c}\text { Aerodynamic } \\
\text { Size Measurement }\end{array}$ & API Specificity & $\begin{array}{l}\text { Mass-Weighted } \\
\text { APSD }\end{array}$ & $\begin{array}{c}\text { Number- } \\
\text { Weighted APSD }\end{array}$ & $\begin{array}{l}\text { Assumption of } \\
\text { Particle Sphericity }\end{array}$ \\
\hline ToF & $x$ & & & $x$ & $x$ \\
\hline E-SPART & $x$ & & & $x$ & \\
\hline SPAMS & $x$ & $x$ & & $x$ & \\
\hline QCMI & $x$ & & $x$ & & \\
\hline Prototype by Fishler et al. (78) & $x$ & & & $x$ & $x$ \\
\hline SPLS & & & & $x$ & $x$ \\
\hline LD & & & $x$ & & $x$ \\
\hline Phase-Doppler Particle Sizing & & & & $x$ & $x$ \\
\hline Microscopy-Automated Image Analysis with RCI & & $x$ & & $x$ & \\
\hline ELPI & $x$ & & & $x$ & \\
\hline
\end{tabular}

$x$ - marks the characteristics that are applicable to each of the methods.

In the case of methods that do not measure the aerodynamic particle size directly, the geometric size distribution is obtained. For those that give the number-weighted APSD, conversion to mass-weighted APSD needs to be done, which causes statistical noise at the large particle end of the distribution. Most of the methodology principles imply the assumption of particle sphericity and/or homogenous density, which makes them unsuitable to be used for dry powder inhalers. (75-79).

API, active pharmaceutical ingredient; APSD, aerodynamic particle size distribution; ToF, Time of Flight; E-SPART, electrical single-particle aerodynamic relaxation time; SPAMS, single particle aerosol mass spectrometry; QCMI, quartz crystal microbalance impactor; SPLS, single-particle light scattering; LD, laser diffractrometry; $R C l$, Raman chemical imaging; ELPI, electrical low-pressure impactor.

active compounds in subsequent dissolution testing. The formation of agglomerates, especially under the air jets, has been demonstrated by scanning electron microscopy (SEM), and reduced surface available for dissolution as well as wetting problems have been reported (49). To avoid this effect, a modified $\mathrm{ACl}(\mathrm{mACl})$ with a stage extension has been designed and compared to the $\mathrm{aACl}$. This comparison revealed a reduction of this effect due to sedimentation being the main deposition mechanism instead of particle impaction. Also, a modified filter stage has been introduced, and SEM analysis showed the formation of a homogenous, almost single-particle layer on the collection membrane with the use of an $\mathrm{mACl}$ (41, $49,50)$. The UniDose, a device that has been developed specifically for separating and collecting the fine particle dose for dissolution testing, also allows the uniform deposition of particles on a filter membrane. It has been shown that, unlike with other methods, the dissolution characteristics are independent of the loaded dose when using this system (39).

The Pharmaceutical Aerosol Deposition Device On Cell Cultures (PADDOCC) collects only the aerosol particles that are assumed to be deposited in the lung (i.e., MMAD typically between 2 and $5 \mu \mathrm{m}$ ) and allows their collection on relevant cell culture models. In contrast to non-physiological impactor systems, the particle sizing and deposition is based on sedimentation and different velocities thereof $(51,52)$.
The Vitrocell Dry Powder Chamber (DPC) (Fig. 1D), which has technically evolved from the PADDOCC, also separates particles of different aerodynamic sizes by their time of flight and uses particle sedimentation as the main deposition mechanism (36). The PADDOCC and Vitrocell DPC are devices designed to allow the collection of particles on Transwell or similar filter supports, which may but do not necessarily have to be coated by epithelial cell culture. Also, it could be possible to adapt these methods for collecting the relevant fraction of DPIs with the goal of analyzing its dissolution behavior.

\section{DISSOLUTION TESTING OF OIDPS}

One of the first dissolution methods designed to test formulations for inhalation in vitro was published in 2000 by McConville and co-workers (53). They used a modified twin stage impinger (TSI) with a 1-mm mesh brass screen introduced in stage 1 , creating an air-liquid interface, and a reservoir for $300 \mathrm{~mL}$ of dissolution medium. Deposited salbutamol particles were able to diffuse through the mesh into the reservoir medium and were quantified in a closed loop configuration. Since these early findings, dissolution methods have been developed that can be classified in four major categories depending on the underlying principle.

\section{Flow-Through Cell Apparatus}

A pre-selection of dispersed particles by $\mathrm{ACl}$ was used for dose collection on a fiber glass membrane by Davies 
and Feddah in 2003 (54). Alternatively, use of the NGI for that purpose is described (55). The deposited particles were then sandwiched with a cellulose acetate filter and mounted into the cell of the flow-through cell apparatus. The dissolution medium was pumped via a high-performance liquid chromatography (HPLC) pump through the cell. The same system was used by Salama et al. in 2008, only that no particle separation based on size was performed prior to dissolution testing (42). The powder was directly weighed on a filter membrane, sandwiched by another filter, and introduced in the flow-through cell. In 2012, May et al. used the $\mathrm{ACl}$ for collecting particles under $5 \mu \mathrm{m}$ before dissolution testing, in theflow-through cell apparatus (49). In contrast to the setup used by McConville, this setting did not create an airliquid interface with the consequence that the dissolution process was flow-rate controlled. The high fluid velocity applied in vitro does not represent the agility of the fluid in the lung, which is rather stationary. Furthermore, the handling of this setup is sensitive to entrapped air in the membrane-drug substance sandwich and in the dead volume of the flow-through cell.

\section{Diffusion Cells and Transwell Setups}

Diffusion controlled systems described in the literature are the horizontal diffusion cell, vertical diffusion cell, and Transwell setups $(42,49,56-60)$. The principle of these techniques differs from the approach used by Davies and Feddah. After dose collection on a membrane, the membrane is placed on top of a reservoir containing the dissolution medium, thus an air-liquid interface is created. Deposited drug particles disintegrate, dissolve, and diffuse into the dissolution medium. The volumes sampled for the analytical finish are replaced by fresh dissolution medium. In case of the horizontal and vertical diffusion cells and the adapted Transwell setup described by May et al., the acceptor solution is continuously stirred to avoid concentration gradient-based diffusion effects. In the case of the vertical diffusion cell, the setup uses a $1000 \mathrm{~mL}$ reservoir for the dissolution medium that is being circulated at a specific flow rate through the diffusion cell $(42,49,60)$. The Transwell setup described by Arora et al. omits any stirring of the dissolution medium but requires a small volume of dissolution medium in the donor compartment (58). This again leads to the absence of an air-liquid interface and additionally it was shown that adding dissolution medium on the membrane led to a decrease of the dissolution rate (59). The same method was applied by Rohrschneider et al. by using the standard Transwell and the modified Transwell, which was first used by May et al (59). The modified Transwell was obtained by thermoforming a small plastic edge on the Transwell support after removing the membrane, so that other types of membranes could be used in this setup $(41,59,60)$. Although the principle of these diffusion cells is similar, the Transwell setup was designed with respect to the limited availability of fluid for dissolution on the epithelia in the respiratory tract. Consequently, the volume of dissolution media used with the Transwell setups is reduced to a few milliliters compared to 100$1000 \mathrm{~mL}$ used in other diffusion cell techniques $(42,49)$.

After particle collection using an $\mathrm{ACl}$, the membranes were placed particle side facing down on the Transwell membrane (58). Collecting particles on filter papers by using the $\mathrm{ACl}$ or $\mathrm{NGI}$ and then placing them in the Transwell inserts but with particles facing upwards is also described (59). May et al. used the $\mathrm{mACl}$ in a setting that allowed for collection of particles directly on the Transwell inserts (60). The test conditions have to be maintained at $37^{\circ} \mathrm{C}$ and $100 \%$ relative humidity to avoid evaporation of the low volumes of dissolution media.

\section{USP $<2>$ Paddle Apparatus}

The third category of dissolution techniques applied for testing of OIDPs is the USP $<2>$ paddle apparatus. This device has been used for decades in standardized in vitro performance testing of solid dosage forms. An adapted setup for dissolution testing of aerodynamically classified particles was published by Son and McConville in 2009 (61). An NGI was used for selection of particles with the relevant aerodynamic size and deposition on a polycarbonate membrane. The membrane was subsequently placed in a modified histology cassette and subjected to dissolution. A setup with 150-mL vessels and smaller paddles was used with the modified histology cassettes in order to use a small dissolution media volume. Use of the NGI collection cup with removable membrane holder improved the performance in this paddle-overdisk dissolution setup (48).

In 2012, May et al. described a comparable setup by also using commercially available membrane holders, consisting of a watch glass and a polymeric screen to keep the membrane in place $(41,49)$. This method was optimized by the use of the $\mathrm{mACl}$ for particle collection and the addition of the surfactant, dipalmitoylphosphatidylcholine (DPPC) (50).

\section{Dissolution and Absorption Simulation Tool - Dissolvlt}

The fourth method is represented by the Dissolvit system (Fig. 1C), in which the dissolution medium flows past a membrane that comes in contact with the particles - a 
configuration used to simulate the in vitro dissolution and absorption of inhaled dry powder drug substances in the lung. This method is both diffusion and flow-rate controlled. A precision-controlled pump maintains a constant flow of blood simulant medium over an air-blood barrier model, which consists of a membrane covered on one side with artificial mucus. The particles are deposited on a circular microscope glass cover slip, which comes in contact with the mucus-covered side of the membrane. The thickness of the so-modeled in vitro air-blood barrier in the Dissolvlt device exceeds that of the epithelium in the deep lung. Therefore, the assumption is that the retention time would be longer compared to the in vivo situation. Moreover, it was shown that retention times of drug substances depended on the amount of lipids in the artificial mucus (44). The artificial mucus consisted of polyethylene oxide in an aqueous phosphate buffer solution with phospholipids added. The behavior of the particles during the dissolution process was observed microscopically. For particle deposition, the Preciselnhale aerosol generator was used $(44,62,63)$.

\section{MEMBRANES}

Often, dissolution experiments were undertaken using membranes on which aerosol particles were deposited prior to dissolution. A variety of membranes with a large range of pore sizes are commercially available and have been used in different studies for particle collection, and subsequently, for dissolution experiments (Table 2).The different membrane types may have an impact on the final dissolution kinetics observed (60). It is generally accepted that the affinity of the substance to be tested for the membrane material is a critical factor and should be determined prior to the experiment. Furthermore, it is important to ascertain that the diffusion rate through the membrane is not the rate-limiting step, the dissolution process is. For example, cellulose acetate dialysis membranes showed a slower release for hydrocortisone compared to polycarbonate membranes, and a twofold increase in dissolution was observed $(48,61)$. For budesonide, polycarbonate membranes presented a lower permeability than Isopore polycarbonate, and polyester membranes had a strong substance-retaining effect and showed the slowest diffusion (60). The tests indicate substance-specific differences in the diffusion of APIs through different types of membranes (41).

\section{DISSOLUTION MEDIA}

Another critical factor is the medium used for dissolution testing, a choice which strongly depends on the purpose of the study and the compound investigated. In the development stages, using media as close as possible to the biological fluids is relevant, but for routine quality control, simple dissolution media are preferred because of their higher reproducibility, lower costs, and ease of preparation (64). A wide range of media has been tested, buffered in the $\mathrm{pH}$ range of 6.8-7.4 and ranging from simple compositions like phosphate buffer to simulated lung fluids (SLF) containing an array of proteins, lipids, and surfactants, like the most abundant pulmonary surfactant, $\operatorname{DPPC}(42,49,58,64-66)$. The most recently developed SLF is the synthetic lung fluid based on human respiratory tract lining fluid composition, proposed by Kumar et al. This medium showed biocompatibility with the human A549 cell line and good correlation of the dissolution behavior of inhalable products with the API's solubility characteristics (67).

Although the SLFs have the advantage of being the most physiologically relevant media, they have a complex composition and in some cases also present a low buffering effect, making them unsuitable for formulations that show $\mathrm{pH}$ dependency or sustained release dissolution profiles. For one SLF it has been observed that the $\mathrm{pH}$ increases in $24 \mathrm{~h}$ from 7.4 to 8.8 (48). In addition, Son et al. showed that for budesonide, the dissolution profiles in phosphate buffered saline (PBS) and phosphate buffer $\mathrm{pH} 7.4$ are similar to the ones obtained in SLF (48). Furthermore, for fluticasone propionate and beclomethasone dipropionate, the solubility values in water were unaltered from those in PBS (58). The types and volumes of dissolution media used with the different test settings are presented in Table 3.

\section{COMBINED DISSOLUTION AND TRANSPORT STUDIES ON CELL CULTURES}

Transport studies on epithelial cell culture models are being used for screening potential drug candidates for pulmonary delivery and aiding the development of inhaled formulations. They were initially done by exposing the cell cultures to solutions or suspensions of the drug to be tested. These types of studies do not account for the fact that in the lung, the particles deposited will not be submerged since the lining fluid is present in a very thin layer, thus erosion, dissolution, and subsequent absorption will start from below the particles. As discussed previously, dissolution of the particles on the surface of the lung epithelia might be the rate-limiting step, so transport of drugs in solution will differ from suspension, and even more so when deposited as a powder. To improve the in vivo relevance of these studies for powders for inhalation, different methods have been used to deposit drug particles on epithelial cell layers grown at an air-liquid interface $(51,52,68-73)$. 
Table 2. Types of Membranes Used in the Dissolution Testing of OIDP

\begin{tabular}{|c|c|c|c|c|}
\hline Membrane Material & $\begin{array}{l}\text { Pore } \\
\text { Size / } \\
\text { MWCO }\end{array}$ & Substance Tested & Dissolution Test Setting & Ref. \\
\hline Regenerated Cellulose & $0.45 \mu \mathrm{m}$ & $\begin{array}{l}\text { Budesonide } \\
\text { Fenoterol } \mathrm{HBr}\end{array}$ & $\begin{array}{l}\text { Flow through cell } \\
\text { Franz cell } \\
\text { Paddle apparatus } \\
\text { Modified Transwell }\end{array}$ & $(41,49)$ \\
\hline Cellulose Acetate & $0.45 \mu \mathrm{m}$ & $\begin{array}{l}\text { Budesonide } \\
\text { Fluticasone propionate } \\
\text { Triamcinolone acetonide }\end{array}$ & Flow through cell & (54) \\
\hline \multirow{2}{*}{$\begin{array}{l}\text { Cellulose Acetate Dialysis } \\
\text { Membrane }\end{array}$} & $3.5 \mathrm{kDa}$ & \multirow{2}{*}{ Hydrocortisone } & \multirow{2}{*}{ Paddle apparatus with histology cassette } & \multirow{2}{*}{$(61)$} \\
\hline & $12 \mathrm{kDa}$ & & & \\
\hline \multirow{5}{*}{ Polycarbonate } & \multirow[t]{2}{*}{$0.4 \mu \mathrm{m}$} & Budesonide & $\begin{array}{l}\text { Franz cell } \\
\text { Paddle apparatus } \\
\text { Transwell }\end{array}$ & $(41,60)$ \\
\hline & & Ciclesonide & Transwell & (59) \\
\hline & $1 \mu \mathrm{m}$ & Hydrocortisone & $\begin{array}{c}\text { Paddle apparatus with } \\
\text { modified histology cassette }\end{array}$ & \multirow[b]{2}{*}{$(48,61)$} \\
\hline & $0.05 \mu \mathrm{m}$ & $\begin{array}{c}\text { Budesonide } \\
\text { Albuterol sulphate }\end{array}$ & $\begin{array}{l}\text { Paddle apparatus with impaction insert } \\
\text { membrane }\end{array}$ & \\
\hline & $0.03 \mu \mathrm{m}$ & $\begin{array}{c}\text { Budesonide } \\
\text { Fluticasone propionate }\end{array}$ & Dissolvlt & (44) \\
\hline Isopore Polycarbonate & $0.4 \mu \mathrm{m}$ & $\begin{array}{l}\text { Budesonide } \\
\text { Fenoterol } \mathrm{HBr}\end{array}$ & $\begin{array}{l}\text { Modified Transwell } \\
\text { Paddle apparatus }\end{array}$ & (41) \\
\hline \multirow[b]{2}{*}{ Polyester } & \multirow[b]{2}{*}{$0.4 \mu \mathrm{m}$} & Budesonide & Transwell & (41) \\
\hline & & $\begin{array}{c}\text { Budesonide } \\
\text { Flunisolide } \\
\text { Triamcinolone acetonide } \\
\text { Fluticasone propionate } \\
\text { Beclomethasone dipropionate }\end{array}$ & Transwell & (58) \\
\hline Polyvinylidene Difluoride & $0.22 \mu \mathrm{m}$ & $\begin{array}{c}\text { Budesonide } \\
\text { Flunisolide } \\
\text { Triamcinolone acetonide } \\
\text { Fluticasone propionate } \\
\text { Beclomethasone dipropionate }\end{array}$ & $\begin{array}{l}\text { After particle collection, the membrane was } \\
\text { placed, particles side facing down, over the } \\
\text { Transwell polyester membrane }\end{array}$ & (58) \\
\hline Nitrocellulose & $0.45 \mu \mathrm{m}$ & Disodium cromoglycate & Flow through cell & (42) \\
\hline Filter Paper (Fisherbrand Q8) & NA & $\begin{array}{l}\text { Ciclesonide } \\
\text { Budesonide } \\
\text { Fluticasone propionate }\end{array}$ & Modified Transwell & (59) \\
\hline
\end{tabular}

OIDP = Orally inhaled drug products; $M W C O=$ molecular weight cut-off; $N A=$ not applicable 
Table 3. Dissolution Test Methods and Media Used

\begin{tabular}{|c|c|c|c|c|c|c|}
\hline Dissolution Setting & Medium & $\begin{array}{c}\text { Medium } \\
\text { Volume }(\mathrm{mL})\end{array}$ & Substance Tested & $\begin{array}{l}\text { Stirring speed } \\
\text { / Flow rate }\end{array}$ & $\begin{array}{l}\text { Air-liquid } \\
\text { interface }\end{array}$ & Ref. \\
\hline \multirow{2}{*}{$\begin{array}{l}\text { USP } 2 \text { Paddle Apparatus: } \\
\text { 150-mL vessels with mini } \\
\text { paddles + histology cassette }\end{array}$} & SLF & \multirow[b]{2}{*}{100} & \multirow[b]{2}{*}{ Hydrocortisone } & \multirow[b]{2}{*}{$50 \mathrm{rpm}$} & \multirow[b]{2}{*}{-} & \multirow[b]{2}{*}{$(61)$} \\
\hline & Modified SLF (SLF + 0.02\% w/v DPPC) & & & & & \\
\hline USP 2 Paddle Apparatus & $0.05 \mathrm{M}$ phosphate buffer $\mathrm{pH} 7.4$ & 1000 & $\begin{array}{c}\text { Disodium } \\
\text { cromoglycate }\end{array}$ & $50 \mathrm{rpm}$ & - & $(42)$ \\
\hline \multirow{2}{*}{$\begin{array}{c}\text { Paddle Over Disk: } \\
\text { Membrane Holder (Watch } \\
\text { Glass + Plastic Mesh) }\end{array}$} & PBS pH 7.4 & 1000 & $\begin{array}{c}\text { Budesonide } \\
\text { Fenoterol } \mathrm{HBr}\end{array}$ & $\begin{array}{l}100 \mathrm{rpm} \\
140 \mathrm{rpm}\end{array}$ & - & $\begin{array}{r}(49, \\
50) \\
\end{array}$ \\
\hline & $P B S+0.02 \%$ DPPC & 1000 & Budesonide & $100 \mathrm{rpm}$ & - & $(50)$ \\
\hline \multirow{5}{*}{$\begin{array}{c}\text { Paddle Over Disk: } \\
\text { Impaction Insert Membrane } \\
\text { Holder }\end{array}$} & $0.2 \mathrm{M}$ phosphate buffer, $\mathrm{pH} 7.4$ & \multirow{5}{*}{300} & \multirow{5}{*}{$\begin{array}{l}\text { Budesonide } \\
\text { Salbutamol }\end{array}$} & \multirow{5}{*}{$\begin{array}{l}50,75,100 \\
\text { rpm }\end{array}$} & - & \multirow{5}{*}{$(48$} \\
\hline & PBS & & & & - & \\
\hline & $P B S+D P P C$ & & & & - & \\
\hline & PBS + polysorbate 80 & & & & - & \\
\hline & SLF & & & & - & \\
\hline \multirow{6}{*}{ Flow Through Cell } & Water & \multirow{4}{*}{$10-420$} & \multirow{4}{*}{$\begin{array}{l}\text { Budesonide } \\
\text { Fluticasone } \\
\text { propionate } \\
\text { Triamcinolone } \\
\text { acetonide }\end{array}$} & \multirow{4}{*}{$0.7 \mathrm{~mL} / \mathrm{min}$} & \multirow{4}{*}{-} & \multirow{4}{*}{$(54$} \\
\hline & Acidic SLF (pH 3) & & & & & \\
\hline & Alkaline SLF (pH 9) & & & & & \\
\hline & $\mathrm{SLF}+0.02 \% \mathrm{DPPC}$ & & & & & \\
\hline & PBS pH 7.4 & $10-60$ & $\begin{array}{l}\text { Budesonide } \\
\text { Fenoterol } \mathrm{HBr}\end{array}$ & $1 \mathrm{~mL} / \mathrm{min}$ & - & $(49)$ \\
\hline & $0.05 \mathrm{M}$ phosphate buffer $\mathrm{pH} 7.4$ & 1000 & $\begin{array}{c}\text { Disodium } \\
\text { cromoglycate }\end{array}$ & $0.5 \mathrm{~mL} / \mathrm{min}$ & - & $(42)$ \\
\hline \multirow[b]{2}{*}{ Modified Vertical Diffusion Cell } & PBS pH 7.4 & 1000 & Budesonide & $100 \mathrm{rpm}$ & + & $(49)$ \\
\hline & $0.05 \mathrm{M}$ phosphate buffer $\mathrm{pH} 7.4$ & 1000 & $\begin{array}{l}\text { Disodium } \\
\text { cromoglycate }\end{array}$ & $5 \mathrm{~mL} / \mathrm{min}$ & + & $(42)$ \\
\hline \multirow{6}{*}{ Transwell } & Water (distilled, deionized) & $1.4+0.04$ & $\begin{array}{l}\text { Fluticasone } \\
\text { propionate } \\
\text { Beclomethasone } \\
\text { dipropionate } \\
\end{array}$ & NA & - & $(58)$ \\
\hline & Water $+0.5 \%$ Tween 80 & $1.4+0.5$ & $\begin{array}{l}\text { Budesonide } \\
\text { Fluticasone } \\
\text { propionate } \\
\text { Ciclesonide }\end{array}$ & $200 \mathrm{rpm}$ & - & $(80)$ \\
\hline & PBS pH 7.4 & $1.4+0.04$ & $\begin{array}{l}\text { Budesonide } \\
\text { Flunisolide } \\
\text { Triamcinolone } \\
\text { acetonide }\end{array}$ & NA & - & $(58)$ \\
\hline & PBS pH 7.4 & $2.6 / 3.85$ & Budesonide & NA / 140 rpm & + & $(60)$ \\
\hline & $\mathrm{PBS}+0.5 \% \mathrm{SDS}$ & $1.5+0.1$ & $\begin{array}{l}\text { Budesonide } \\
\text { Fluticasone } \\
\text { propionate } \\
\text { Ciclesonide }\end{array}$ & NA & - & $(59)$ \\
\hline & SLF & $\begin{array}{l}600 \mu \mathrm{\mu l} / \text { well } \\
\text { base-plate }\end{array}$ & $\begin{array}{c}\text { Fluticasone } \\
\text { propionate } \\
\text { Beclomethasone } \\
\text { dipropionate } \\
\end{array}$ & NA & + & $(67)$ \\
\hline \multirow{2}{*}{$\begin{array}{l}\text { Dissolvit (Flow Past Dissolution } \\
\text { Cell) }\end{array}$} & \multirow{2}{*}{$\begin{array}{l}\text { Blood simulant (phosphate buffer } \\
0.1 \mathrm{M}, \mathrm{pH} 7.4+4 \% \mathrm{w} / \mathrm{v} \text { albumin) }\end{array}$} & $\begin{array}{c}24 \text { (for } 1 \mathrm{~h} \\
\text { test run) }\end{array}$ & Budesonide & $0.4 \mathrm{~mL} / \mathrm{min}$ & - & \multirow{2}{*}{ (44) } \\
\hline & & $\begin{array}{c}192 \text { (for } 8 \mathrm{~h} \\
\text { test run) }\end{array}$ & $\begin{array}{l}\text { Fluticasone } \\
\text { propionate }\end{array}$ & $0.4 \mathrm{~mL} / \mathrm{min}$ & - & \\
\hline
\end{tabular}

SLF, simulated lung fluid; DPPC, dipalmitoylphosphatidylcholine; PBS, phosphate buffered saline; SDS, sodium dodecyl sulphate; NA, not applicable; " + " marks the presence of an air-liquid interface to which the powder is exposed in the dissolution setup; "- marks the absence of this interface. 
Data reported in the literature show a significant difference in results even when using the same cell models, probably because of the use of different particle deposition methods together with different formulations and different conditions in which the cells were treated. These results are presented in detail in a review paper by Haghi et al. (74). Apart from the high number of factors leading to an increased variability in results, the use of cell culture models is complex, time-consuming, and expensive, which makes them not desirable for routine quality control, but it nevertheless is supporting research and development efforts with valuable data about API uptake.

\section{CONCLUSION AND OUTLOOK}

In 2012, May et al. compared the vertical diffusion cell, flow-through cell, and USP paddle apparatus for dissolution testing of powders for inhalation. These three devices were capable of discriminating between the different solubility characteristics of the drug substances, but only the USP paddle apparatus showed good reproducibility of the dissolution kinetics and the capability of ranking the drugs corresponding to their solubilities (49). Most of the techniques described in literature show a poor relationship to the in vivo situation due to the use of large dissolution medium volumes (100-1000 mL), except for the Transwell and modified Transwell systems, which give the opportunity to test the dissolution behavior of compounds in biorelevant fluid volumes but do not account for concentration gradients caused in vivo by absorption and turnover of fluids (49, $58,60)$. Larger volumes of dissolution media for in vitro testing may be needed to ascertain solubility conditions.

The Dissolvit system can differentiate between formulations and relate them to pharmacokinetic parameters like $C_{\max }$ and $t_{\max }$. Also, a relationship between results obtained with this setup and data from clinical trials, as well as studies on isolated and perfused rat lung has been reported (44).

As APSD characterization is a prerequisite to dissolution testing with clinical relevance, the focus of adopting existing methods has made great progress, such as the $\mathrm{mACl}$ with a stage extension described by May et al. (50). Major developmental steps towards robust, reliable, and reproducible methods for in vitro dissolution testing of APIs have been published over the last years (Table 3), but still more work remains to develop a valid standardized approach.

\section{ACKNOWLEDGEMENTS}

The authors disclosed no funding related to this article.

\section{CONFLICT OF INTEREST}

The authors disclosed no conflicts of interest related to this article.

\section{REFERENCES}

1. Labiris, N. R,; Dolovich, M. B. Pulmonary drug delivery. Part I: physiological factors affecting therapeutic effectiveness of aerosolized medications. Br. J. Clin. Pharmacol. 2003, 56, 588599. DOI: 10.1046/j.1365-2125.2003.01892.x.

2. Patton, J. S.; Fishburn, C. S.; Weers, J. G. The lungs as a portal of entry for systemic drug delivery. Proc. Am. Thorac. Soc. 2004, 1, 338-344. DOI: 10.1513/pats.200409-049TA.

3. Patton, J. S.; Byron, P. R. Inhaling medicines: delivering drugs to the body through the lungs. Nat. Rev. Drug. Discov. 2007, 6, 67-74. DOI: 10.1038/nrd2153.

4. Ruge, C. A.; Kirch, J.; Lehr, C.-M. Pulmonary drug delivery: From generating aerosols to overcoming biological barrierstherapeutic possibilities and technological challenges. Lancet Respir. Med. 2013, 1, 402-413. DOI: 10.1016/S22132600(13)70072-9.

5. Henning, A.; Schneider, M.; Nafee, N.; Muijs, L.; Rytting, E.; Wang, X.; Kissel, T.; Grafahrend, D.; Klee, D.; Lehr, C.-M. Influence of particle size and material properties on mucociliary clearance from the airways. J. Aerosol. Med. Pulm. Drug. Deliv. 2010, 23, 233-241. DOI: 10.1089/jamp.2009.0806.

6. Agnew, J. E.; Sutton, P. P.; Pavia, D.; Clarke, S. W. Radioaerosol assessment of mucociliary clearance: towards definition of a normal range. Br. J. Radiol. 1986, 59, 147-151. DOI: 10.1259/0007-1285-59-698-147.

7. Sanders, M. Inhalation therapy: an historical review. Prim. Care. Respir. J. 2007, 16, 71-81. DOI: 10.3132/pcrj.2007.00017.

8. Noymer, P.; Biondi, S.; Myers, D.; Cassella, J. Pulmonary delivery of therapeutic compounds for treating CNS disorders. Ther. Deliv. 2011, 2, 1125-1140.

9. Islam, N.; Rahman, S. Improved treatment of nicotine addiction and emerging pulmonary drug delivery. Drug Discov. Ther. 2012, 6, 123-132. DOI: 10.5582/ddt.2012.v6.3.123.

10. Tuinman, P. R.; Dixon, B.; Levi, M.; Juffermans, N. P.; Schultz, M. J. Nebulized anticoagulants for acute lung injury - a systematic review of preclinical and clinical investigations. Crit. Care. 2012, 16, 1-10. DOI: 10.1186/cc11325.

11. Siekmeier, R.; Scheuch, G. Treatment of systemic diseases by inhalation of biomolecule aerosols. J. Physiol. Pharmacol. 2009, $60,15-26$.

12. Hinds, W. C. Aerosol Technology: Properties, Behavior, and Measurement of Airborne Particles. 2nd ed. John Wiley \& Sons, Inc; 1999.

13. Hastedt, J. E.; Bäckman, P.; Clark, A. R.; Doub, W.; Hickey, A.; Hochhaus, G.; Kuehl, P. J.; Lehr, C.-M.; Mauser, P.; McConville, J.; 
Niven, R.; Sakagami, M.; Weers, J. G. Scope and relevance of a pulmonary biopharmaceutical classification system AAPS/FDA/ USP Workshop, March 16-17, 2015, Baltimore, MD. AAPS Open 2016, 2, 1-20. DOI: 10.1186/s41120-015-0002-x.

14. Patton, J. S. Mechanisms of macromolecule absorption by the lungs. Adv. Drug Deliv. Rev. 1996, 19, 3-36.

15. Gray, V. A.; Hickey, A. J.; Balmer, P.; Davies, N. M.; Dunbar, C.; Foster, T. S.; Olsson, B. L.; Sakagami, M.; Shah, V. P.; Smurthwaite, M. J.; Veranth, J. M.; Zaidi, K. The inhalation ad hoc advisory panel for the USP performance tests of inhalation dosage forms. Pharmacopeial Forum. 2008, 34, 1068-1074.

16. Labouta, H. I.; Schneider, M. Tailor-made biofunctionalized nanoparticles using layer-by-layer technology. Int. J. Pharm. 2010, 395, 236-242. DOI: 10.1016/j.jpharm.2010.05.019.

17. Riley, T.; Christopher, D.; Arp, J.; Casazza, A.; Colombani, A.; Cooper, A.; Dey, M.; Maas, J.; Mitchell, J.; Reiners, M.; Sigari, N.; Tougas, T.; Lyapustina, S. Challenges with developing in vitro dissolution tests for orally inhaled products (OIPs). AAPS PharmSciTech 2012, 13, 978-989. DOI: 10.1208/s12249-0129822-3.

18. Forbes, B.; Bäckman, P.; Christopher, D.; Dolovich, M.; Li, B. V.; Morgan, B. In vitro testing for orally inhaled products: developments in science-based regulatory approaches. AAPS J. 2015, 17, 837-852. DOI: 10.1208/s12248-015-9763-3.

19. Guideline on the Pharmaceutical Quality of Inhalation and Nasal Products; EMEA/CHMP/QWP/49313/2005 Corr; Committee for Medicinal Products for Human Use (CHMP). European Medicines Agency. London; 2006.

20. Metered Dose Inhaler (MDI) and Dry Powder Inhaler (DPI) Drug Products. Chemistry, Manufacturing, and Controls Documentation; Draft Guidance for Industry; U.S. Department of Health and Human Services, Food and Drug Administration, Center for Drug Evaluation and Research (CDER), U.S. Government Printing Office, Washington, DC, 1998.

21. Brown, C. K.; Friedel, H. D.; Barker, A. R.; Buhse, L. F.; Keitel, S.; Cecil, T. L.; Kraemer, J.; Morris, J. M.; Reppas, C.; Stickelmeyer, M. P.; Yomota, C.; Shah, V. P. Meeting Report: FIP/AAPS Joint Workshop Report: Dissolution/In Vitro Release Testing of Novel/ Special Dosage Forms. AAPS PharmSciTech 2011, 12, 782-794. DOI: 10.1208/s12249-011-9634-x.

22. Adams, W. P.; Ahrens, R. C.; Chen, M.; Christopher, D.; Chowdhury, B. A.; Conner, D. P.; Dalby, R.; Fitzgerald, K.; Hendeles, L.; Hickey, A. J.; Hochhaus, G.; Laube, B. L.; Lucas, P.; Lee, S. L.; Lyapustina, S.; Li, B.; O'Connor, D.; Parikh, N.; Parkins, D. A.; Peri, P.; Pitcairn, G. R.; Riebe, M.; Roy, P.; Shah, T.; Singh, G. J. P.; Sharp, S. S.; Surman, J. D.; Weda, M.; Woodcock, J.; Yu, L. Demonstrating bioequivalence of locally acting orally inhaled drug products (OIPs): workshop summary report. J. Aerosol Med. Pulm. Drug Deliv. 2010, 23, 1-29. DOI: 10.1089/jamp.2009.0803.

23. Horhota, S. T. Evaluation of comparative performance of orally inhaled drug products in view of the classical bioequivalence paradigms: an analysis of the current scientific and regulatory dilemmas of inhaler evaluation. J. Aerosol Med. Pulm. Drug Deliv. 2014, 27, 408-413. DOI: 10.1089/jamp.2014.1144.

24. Hochhaus, G.; Davis-Cutting, C.; Oliver, M.; Lee, S. L.; Lyapustina, $\mathrm{S}$. Current scientific and regulatory approaches for development of orally inhaled and nasal drug products: Overview of the IPACRS/University of Florida Orlando Inhalation Conference. AAPS J. 2015, 17, 1305-1311. DOI: 10.1208/s12248-015-9791-z.

25. Forbes, B. The role of particle dissolution and cellular uptake testing in OIP bioequivalence determinations Orlando Inhalation Conference: Approaches to International Regulation, IPAC-RS, Orlando, FL, March 19, 2014. https://ipacrs.org/assets/uploads/ outputs/03_-_Day_2_OIC_2014_Forbes.pdf

26. Gray, V. A. Meeting report: AAPS workshop on inhalation product biopharmaceutical classification system development: challenges and opportunities. Dissolution Technol. 2015, 52-55. DOI: 10.14227/DT220315P52.

27. Amidon, G. L.; Lennernäs, H.; Shah, V. P.; Crison, J. R. A theoretical basis for a biopharmaceutic drug classification: the correlation of in vitro drug product dissolution and in vivo bioavailability. Pharm. Res. 1995, 12, 413-420. DOI: 10.1023/A:1016212804288.

28. Eixarch, H.; Haltner-Ukomadu, E.; Beisswenger, C.; Bock, U. Drug delivery to the lung: Permeability and physicochemical characteristics of drugs as the basis for a pulmonary biopharmaceutical classification system (pBCS). J. Epithel. Biol. Pharmacol. 2010, 3, 1-14. DOI: 10.2174/18750443010030100001.

29. Velaga, S. P.; Djuris, J.; Cvijic, S.; Rozou, S.; Russo, P.; Colombo, G.; Rossi, A. Dry powder inhalers: an overview of the in vitro dissolution methodologies and their correlation with the biopharmaceutical aspects of the drug products. Eur. J. Pharm. Sci. 2018, 113, 18-28. DOI: 10.1016/j.ejps.2017.09.002.

30. Mehta, P. Dry powder inhalers: a focus on advancements in novel drug delivery systems. J. Drug Deliv. 2016, 8290963. DOI: 10.1155/2016/8290963.

31. Narang, A. S.; Mahato, R. I. Biopharmaceutics of inhalation drug delivery: at the interface of drug, device, formulation, and patient characteristics. AAPS Newsmagazine 2017, 14-18.

32. Copley Scientific: Inhaler Testing Brochure 2015. http://www. copleyscientific.com/downloads/brochures.

33. Gupta, V.; Thomas, C.; Ahsan, F. Principles and practice of pulmonary drug delivery. Ch. 15 in: Targeted Delivery of Small and Macromolecular Drugs. Narang, A. S.; Mahato, R. I.; Eds.; CRC Press: Boca Raton, FL; 2010, pp. 371-419. DOI: 10.1201/9781420087734-c15.

34. Timisina, M. P.; Martin, G. P.; Marriot, C.; Ganderton, D.; Yianneskis, M. Drug delivery to the respiratory tract using dry powder inhalers. Int. J. Pharm. 1994, 101, 1-13.

35. Muralidharan, P.; Hayes, D. Jr.; Mansour, H. M. Dry powder inhalers in COPD, lung inflamation and pulmonary infections. Expert. Opin. Drug Deliv. 2015, 12, 947-962. DOI: 10.1517/17425247.2015.977783. 
36. Hittinger, M.; Barthold, S.; Siebenbürger, L.; Zäh, K.; Gress, A.; Guenther, S.; Wiegand, B.; Boerger, C.; Berger, M.; Krebs, T.; Groß, H.; Lehr, C.-M. Proof of concept of the VITROCELL dry powder chamber: a new in vitro test system for the controlled deposition of aerosol formulations. RDD Europe 2017. 2017, 2, 283-288.

37. Bonam, M.; Christopher, D.; Cipolla, D.; Donovan, B.; Goodwin, D.; Holmes, S.; Lyapustina, S.; Mitchell, J.; Nichols, S.; Pettersson, G.; Quale, C.; Rao, N.; Singh, D.; Tougas, T.; van Oort, M.; Walther, B.; Wyka, B. Minimizing variability of cascade impaction measurements in inhalers and nebulizers. AAPS PharmSciTech 2008, 9, 404-413. DOI: 10.1208/s12249-008-9045-9.

38. Mitchell, J. P.; Nagel, M. W.; Doyle, C. C.; Ali, R. S.; Avvakoumova, V. I.; Christopher, J. D.; Quiroz, J.; Strickland, H.; Tougas, T.; Lyapustina, S. Relative precision of inhaler aerodynamic particle size distribution (APSD) metrics by full resolution and abbreviated andersen cascade impactors (ACls): part 1. AAPS PharmSciTech 2010, 11, 843-851. DOI: 10.1208/s12249-010-9452-6.

39. Price, R.; Shur, J. Apparatus and method for determination of the fine particle dose of a powder inhalation formulation. WO Patent Application 2017051180A1, March 30, 2017. https:// patents.google.com/patent/WO2017051180A1/

40. Gerde, P. Deposition of aerosols for dissolution experiments: how to combine the one with the other? Drug Delivery to the Lungs Conference (DDL25). The Aerosol Society, Edinburgh, Scotland, December 10-12, 2014. https://aerosol-soc.com/abstracts/ deposition-aerosols-dissolution-experiments-combine-one/\#

41. May, S. Dissolution testing of powders for inhalation. Doctoral Thesis [online], Universität des Saarlandes, Saarbrücken, Germany; Dec 2013. DOI: 10.22028/D291-22927.

42. Salama, R. O.; Traini, D.; Chan, H.-K.; Young, P. M. Preparation and characterisation of controlled release co-spray dried drug-polymer microparticles for inhalation 2: Evaluation of in vitro release profiling methodologies for controlled release respiratory aerosols. Eur. J. Pharm. Biopharm. 2008, 70, 145152. DOI: 10.1016/j.ejpb.2008.04.009.

43. Balducci, A. G.; Steckel, H.; Guarneri, F.; Rossi, A.; Colombo, G.; Sonvico, F.; Cordts, E.; Bettini, R.; Colombo, P.; Buttini, F. High shear mixing of lactose and salmeterol xinafoate dry powder blends: Biopharmaceutic and aerodynamic performances. J. Drug Deliv. Sci. Technol. 2015, 30, 443-449. DOI: 10.1016/j. jddst.2015.07.010.

44. Gerde, P.; Malmlöf, M.; Havsborn, L.; Sjöberg, C.-O.; Ewing, P.; Eirefelt, S.; Ekelund, K. Dissolvlt: an in vitro method for simulating the dissolution and absorption of inhaled dry powder drugs in the lungs. Assay Drug Dev. Technol. 2017, 15, 77-88. DOI: 10.1089/adt.2017.779.

45. Mitchell, J. P.; Nagel, M. W.; Avvakoumova, V.; MacKay, H.; Ali, R. The abbreviated impactor measurement (AIM) concept: part I-influence of particle bounce and re-entrainment-evaluation with a "dry" pressurized metered dose inhaler (pMDI)-based formulation. AAPS PharmSciTech 2009, 10, 243-251. DOI: 10.1208/s12249-009-9202-9.
46. Mitchell, J. P.; Nagel, M. W.; Avvakoumova, V.; MacKay, H.; Ali, R. the abbreviated impactor measurement (AIM) concept: part II - influence of evaporation of a volatile component-evaluation with a "droplet-producing" pressurized metered dose inhaler (pMDI)-based formulation containing ethanol as cosolvent. AAPS PharmSciTech 2009, 10, 252-257. DOI: 10.1208/s12249009-9201-x.

47. Mohan, M.; Lee, S.; Guo, C.; Peri, S. P.; Doub, W. H. Evaluation of abbreviated impactor measurements (AIM) and efficient data analysis (EDA) for dry powder inhalers (DPIs) against the fullresolution next generation impactor (NGI). AAPS PharmSciTech 2017, 18, 1585-1594. DOI: 10.1208/s12249-016-0625-9.

48. Son, Y. J.; Horng, M.; Copley, M.; McConville, J. T. Optimization of an in vitro dissolution test method for inhalation formulations. Dissolution Technol. 2010, 17, 6-13. DOI: 10.14227/DT170210P6.

49. May, S.; Jensen, B.; Wolkenhauer, M.; Schneider, M.; Lehr, C.-M. Dissolution techniques for in vitro testing of dry powders for inhalation. Pharm. Res. 2012, 29, 2157-2166. DOI: 10.1007/ s11095-012-0744-2.

50. May, S.; Jensen, B.; Weiler, C.; Wolkenhauer, M.; Schneider, M.; Lehr, C.-M. Dissolution testing of powders for inhalation: influence of particle deposition and modeling of dissolution profiles. Pharm. Res. 2014, 31, 3211-3224. DOI: 10.1007/ s11095-014-1413-4.

51. Hein, S.; Bur, M.; Kolb, T.; Muellinger, B.; Schaefer, U. F.; Lehr, C.-M. The pharmaceutical aerosol deposition device on cell cultures (PADDOCC) in vitro system: design and experimental protocol. ATLA Altern. to Lab. Anim. 2010, 38, 285-295.

52. Hein, S. Pharmaceutical aerosol deposition device on cell cultures (PADDOCC): development of an in vitro test system based on pulmonary epithelial cells. Doctoral Dissertation [Online], Universität des Saarlandes; Saarbrücken, Germany, Dec 2010. https://publikationen.sulb.uni-saarland.de/ bitstream/20.500.11880/22737/1/DissertationHein15.12.10. pdf (Accessed June 29 2018).

53. McConville, J. T.; Patel, N.; Ditchburn, N.; Tobyn, M. J.; Staniforth, J. N.; Woodcock, P. Use of a novel modified TSI for the evaluation of controlled-release aerosol formulations. I. Drug Dev. Ind. Pharm. 2000, 26, 1191-1198. DOI: 10.1081/DDC-100100991.

54. Davies, N. M.; Feddah, M. R. A novel method for assessing dissolution of aerosol inhaler products. Int. J. Pharm. 2003, 255, 175-187. DOI: 10.1016/S0378-5173(03)00091-7.

55. Riley, T.; Jones, A.; Huescar, M. B.; Roche, T. In vitro method for determining the dissolution rate of inhalation aerosols. Respir. Drug Deliv. 2008. 2008, 2, 541-544.

56. Cook, R. O.; Pannu, R. K.; Kellaway, I. W. Novel sustained release microspheres for pulmonary drug delivery. J. Control. Release 2005, 104, 79-90. DOI: 10.1016/j.jconrel.2005.01.003.

57. Franz, T. J. Percutaneous absorption. On the relevance of in vitro data. J. Invest. Dermatol. 1975, 64, 190-195. DOI: 10.1111/15231747.ep12533356. 
58. Arora, D. ; Shah, K. A.; Halquist, M. S.; Sakagami, M. In vitro aqueous fluid-capacity-limited dissolution testing of respirable aerosol drug particles generated from inhaler products. Pharm. Res. 2010, 27, 786-795. DOI: 10.1007/s11095-010-0070-5.

59. Rohrschneider, M.; Bhagwat, S.; Krampe, R.; Michler, V.; Breitkreutz, J.; Hochhaus, G. Evaluation of the Transwell system for characterization of dissolution behavior of inhalation drugs: effects of membrane and surfactant. Mol. Pharm. 2015, 12, 2618-2624. DOI: 10.1021/acs.molpharmaceut.5b00221.

60. May, S.; Kind, S.; Jensen, B.; Wolkenhauer, M.; Schneider, M.; Lehr, C.-M. Miniature in vitro dissolution testing of powders for inhalation. Dissolution Technol. 2015, 22, 40-51. DOI: 10.14227/ DT220315P40.

61. Son, Y. J.; McConville, J. T. Development of a standardized dissolution test method for inhaled pharmaceutical formulations. Int. J. Pharm. 2009, 382, 15-22. DOI: 10.1016/j. ijpharm.2009.07.034.

62. Gerde, P. Device for studying interaction between particles and lungs. U.S. Patent 8,348,673, Jan 8, 2013.

63. Börjel, M.; Sadler, C. R.; Gerde, P. The Dissolvlt: an in vitro evaluation of the dissolution and absorption of three inhaled dry powder drugs in the lung. Respir. Drug Deliv. 2014. 2014, 2, 439-444.

64. Marques, M. R. C.; Loebenberg, R.; Almukainzi, M. Simulated biologic fluids with possible application in dissolution testing. Dissolution Technol. 2011, 18, 15-28. DOI: 10.1002/jps.23029.

65. Sakagami, M.; Lakhani, D. A. Understanding dissolution in the presence of competing cellular uptake and absorption in the airways. Respir. Drug Deliv. 2012. 2012, 1, 185-192.

66. Griese, M.; Sander Stiftung, W. Pulmonary surfactant in health and human lung diseases: state of the art. Eur. Respir. J. 1999, 13, 1455-1476.

67. Kumar, A.; Terakosolphan, W.; Hassoun, M.; Vandera, K.-K.; Novicky, A.; Harvey, R.; Royall, P. G.; Bicer, E. M.; Eriksson, J.; Edwards, K.; Valkenborg, D.; Nelissen, I.; Hassall, D.; Mudway, I. S.; Forbes, B. A biocompatible synthetic lung fluid based on human respiratory tract lining fluid composition. Pharm. Res. 2017, 34, 2454-2465. DOI: 10.1007/s11095-017-2169-4.

68. Bur, M.; Huwer, H.; Muys, L.; Lehr, C.-M. Drug transport across pulmonary epithelial cell monolayers: effects of particle size, apical liquid volume, and deposition technique. J. Aerosol Med. Pulm. Drug Deliv. 2010, 23, 119-127. DOI: 10.1089/ jamp.2009.0757.

69. Haghi, M.; Traini, D.; Postma, D. S.; Bebawy, M.; Young, P. M. Fluticasone uptake across Calu- 3 cells is mediated by salmeterol when deposited as a combination powder inhaler. Respirology 2013, 18, 1197-1201. DOI: 10.1111/resp.12146.

70. Ong, H. X.; Traini, D.; Bebawy, M.; Young, P. M. Ciprofloxacin is actively transported across bronchial lung epithelial cells using a Calu-3 air interface cell model. Antimicrob. Agents Chemother. 2013, 57, 2535-2540.

71. Ong, H. X.; Traini, D.; Loo, C.-Y.; Sarkissian, L.; Lauretani, G.; Scalia, S.; Young, P. M. Is the cellular uptake of respiratory aerosols delivered from different devices equivalent? Eur. J. Pharm. Biopharm. 2015, 93, 320-327. DOI: 10.1016/j.ejpb.2015.04.012.

72. Haghi, M.; Traini, D.; Bebawy, M.; Young, P. M. Deposition, diffusion and transport mechanism of dry powder microparticulate salbutamol, at the respiratory epithelia. Mol. Pharm. 2012, 9, 1717-1726. DOI: 10.1021/mp200620m.

73. Haghi, M.; Traini, D.; Young, P. In vitro cell integrated impactor deposition methodology for the study of aerodynamically relevant size fractions from commercial pressurised metered dose inhalers. Pharm. Res. 2014, 31, 1779-1787. DOI: 10.1007/ s11095-013-1282-2.

74. Haghi, M.; Ong, H. X.; Traini, D.; Young, P. Across the pulmonary epithelial barrier: Integration of physicochemical properties and human cell models to study pulmonary drug formulations. Pharmacol. Ther. 2014, 144, 235-252. DOI: 10.1016/j. pharmthera.2014.05.003.

75. Mitchell, J.; Bauer, R.; Lyapustina, S.; Tougas, T.; Glaab, V. Non-impactor-based methods for sizing of aerosols emitted from orally inhaled and nasal drug products (OINDPs). AAPS PharmSciTech 2011, 12, 965-988. DOI: 10.1208/s12249-0119662-6.

76. Mitchell, J. Time-of-flight methods for the measurement of the aerodynamic particle size distribution of aerosols from orally inhaled products: points to consider. J. Aerosol Med. Pulm. Drug Deliv. 2015, 28, A-26-A-27. DOI: 10.1089/jam.1999.12.217.

77. Mitchell, J. P.; Nagel, M. W.; Suggett, J. A.; Coppolo, D. P. Obscuring the message: A critical examination of laboratory test methods for orally inhaled products that could lead the user astray: part 1-aerodynamic particle size distribution (APSD). Inhalation 2017, 20-25.

78. Fishler, R.; Verhoeven, F.; de Kruijf, W.; Sznitman, J. Particle sizing of pharmaceutical aerosols via direct imaging of particle settling velocities. Eur. J. Pharm. Sci. 2017, 113, 152-158. DOI: 10.1016/j. ejps.2017.08.016.

79. Telko, M. J.; Hickey, A. J. Aerodynamic and electrostatic properties of model dry powder aerosols: a comprehensive study of formulation factors. AAPS PharmSciTech 2014, 15, 1378-1397. DOI: 10.1208/s12249-014-0144-5.

80. Bhagwat, S.; Schilling, U.; Chen, M. J.; Wei, X.; Delvadia, R.; Absar, M.; Saluja, B.; Hochhaus, G. Predicting pulmonary pharmacokinetics from in vitro properties of dry powder inhalers. Pharm. Res. 2017, 34, 2541-2456. DOI: 10.1007/ s11095-017-2235-y. 